\title{
Hay que evitar totalizar la violencia para poder comprender la paz viva. Entrevista con Juan Gutiérrez ${ }^{* *}$
}

\author{
We must try to avoid totalizing the violence in order to understand \\ the positive peace. Interview with Juan Gutierrez \\ É necessário evitar totalizar a violência para poder compreender \\ a paz viva. Entrevista com Juan Gutiérrez
}

\footnotetext{
* Amador Fernández Savater es co-editor de la casa editorial Acuarela Libros, ensayista ocasional y periodista madrileño, colaborador ahora mismo del periódico digital eldiario.es. Correo electrónico: amador@sindominio.net

** Doctora en Sociología por la Universidad Autónoma de Barcelona. Profesora e investigadora en la academia de Comunicación y Cultura de la Universidad Autónoma de la Ciudad de México. Es miembro del Sistema Nacional de Investigadores en México. Ha ejercido como periodista y productora de radio y televisión en el ámbito noticioso en México y, como corresponsal en el extranjero. Las líneas de investigación que configuran su quehacer académico son la migración y los movimientos sociales, la interculturalidad y la comunicación.Correo electrónico: amarela.varela@uacm.edu.mx

*** Juan Gutiérrez es investigador y asesor por la paz. Estudió filosofía en Hamburgo. Participó en el movimiento estudiantil alemán contra la guerra de Vietnam y contra casi todo. Trabajó ocho años de obrero-asistente social en un astillero. Militó malamente en un partido maoísta. Dirigió un centro de ecología en Madrid, fundó y dirigió un centro de investigaciones para la paz en Gernika (Gernika Gogoratuz que significa «recordando Gernika»). Actualmente, es miembro y asesor de la Asociación 11M Afectados por Terrorismo y de la Red Mundial de Afectados por Violencia Política. Coordina el proyecto "Memoria y procomún" de Medialab-Prado, que reconstruye la memoria de paz de vida en España durante el período 1936-1978. Es también el fundador y coordinador del Proyecto Hebras de Paz Viva (http://hebrasdepaz.org/) laboratorio de acciones e ideas para potenciar la paz. Entrevista recibida el 22/02/2016 y aceptada el 20/07/2016.
} 


\section{Cómo citar}

FERnández SAVATER, A y VAREla Huerta, A. (2016). Guerra y posconflicto en Guatemala: búsqueda de justicia antes y después de los acuerdos de paz. Revista CS, no. 19, pp. 201-216. Cali, Colombia: Facultad de Derecho y Ciencias Sociales, Universidad Icesi.

DOI: http://dx.doi.org/10.18046/recs.i19. 2173 


\section{Resumen}

Abstract

Resumo

Juan Gutiérrez fue invitado por la Universidad Autónoma de Puebla y el Tecnológico de Monterrey, a compartir la experiencia del proyecto "Hebras de Paz" en México. Este proyecto en concreto, y la reflexión de largo aliento de Juan Gutiérrez sobre un concepto fuerte de paz, son especialmente pertinentes e inspiradores en el contexto actual de crisis de los derechos humanos relacionada con la llamada "guerra contra el narcotráfico" en México. ¿Por qué? La perspectiva de Juan Gutiérrez, encarnada en el proyecto “Hebras...”, valora y visibiliza gestos de resistencia y de vida que deconstruyen la lógica de bandos de las guerras y la figura del enemigo. Se trata de "no totalizar la violencia", como sugiere Juan Gutiérrez, es decir, no verla como completa, omnipotente, absoluta; y para ello poner el foco en estos gestos de paz viva que atraviesan los bandos y ponen en valor la humanidad transversal que siempre subyace a las situaciones de conflicto abierto. Juan Gutiérrez y los entrevistadores mantienen un diálogo vivo sobre estas cuestiones desde hace años; y en el contexto del viaje pensaron que podía ser muy valioso compartir estas reflexiones, vivencias y relatos para pensar de otra manera (menos victimizadora y despotenciante) la violencia en México.

PALABRAS CLAVE:

Entrevista | Paz viva | Juan Gutiérrez | México | Hebras de Paz Viva

Juan Gutierrez was invited to share the experience of "Peace Strands Project" in Mexico by the Universidad Autónoma de Puebla and the Tecnológico de Monterrey. This particular project and the long-winded reflection of the interviewee about a strong concept of peace are particularly inspiring and relevant in the actual crisis context of human rights related to the "war on drugs" in Mexico. Why? From his perspective, embodied in the Peace Strands Project, this gives visibility and adds value to resistance and life gestures that deconstruct the logic of the sides of the war and the figure of the enemy. It is about not "totalizing violence", that is, not seeing it as a complete, all-powerful absolute and for it, that for that, to focus on gestures of positive peace crossing the sides and that place value on the traverse humanity always underlying open conflict situations. Juan Gutierrez and the interviewers maintain a 
live dialogue about these issues for years now and, in the context of his trip to Mexico, they thought that it might be valuable to share some thoughts, experiences, and stories to think otherwise the violence in Mexico.

\section{KEYWORDS:}

Interview | Positive Peace | Juan Gutiérrez | México | Strands of Peace

Juan Gutiérrez foi convidado a compartilhar a experiência do projeto "Hebras de Paz" no México pela Universidade Autônoma de Puebla e o Tecnológico de Monterrey. Este projeto em concreto, e a reflexão profunda do entrevistado sobre um conceito forte de paz, são especialmente pertinentes e inspiradores no contexto atual de crise dos direitos humanos relacionada com a chamada "guerra contra o narcotráfico" no México. Por quê? Desde a sua perspectiva situada no projeto "Fios de Paz", esta dá visibilidade e valor a gestos de resistência e de vida que desconstroem a lógica de bandos das guerras e a figura do inimigo. Trata-se de "não totalizar a violência", ou seja, não vê-la como completa, onipotente, absoluta e para isso centrar-se nestes gestos de paz viva que atravessam os bandos e agregam valor a humanidade transversal subjacente às situações de conflito aberto. Juan Gutiérrez e os entrevistadores mantêm um diálogo vivo sobre estas questões já fazem vários anos e, no contexto da viagem, pensaram que podia ser muito valioso compartilhar estas reflexões, vivências e relatos para pensar de outra maneira sobre a violência no México.

\section{PALAVRAS CHAVES:}

Entrevista | Paz viva | Juan Gutiérrez | México | Fios de Paz Viva 


\section{La paz como punto de partida}

Amarela Varela Huerta (AVH): Lo primero que queríamos preguntarte es cuál es tu relación con el tema de la paz, cómo has llegado hasta él.

Juan Gutiérrez (JG): Para responderos, tengo que abrir la autobiografía. Pues bien, en el año 1967 yo residía en Hamburgo y participé muy directamente en los movimientos estudiantiles alemanes que de alguna forma prefiguraron el Mayo del 68 francés. Después de aquello, entré en la onda maoísta que pretendía radicalizar el marxismo. Vivía inmerso en una contradicción, porque mi cultivo de la sensibilidad le debía mucho al 68 alemán, sin embargo militaba en un partido maoísta español que se presentaba como maoísta pero más bien era estalinista, muy rígido y separado de la realidad: la Organización Revolucionaria de Trabajadores (ORT).

La violencia era algo de lo que me separaba espontáneamente. Recuerdo cuando invadimos la Facultad de Filosofía en Hamburgo que estaba en lo alto de una torre. Subimos en masa por la escalera para entrar, pero cubriendo la puerta de cristal había muchos agentes de seguridad armados con pistolas. Yo me puse entonces de espaldas a los de seguridad con las manos levantadas para que la gente se detuviera y no hubiera violencia. No fue una acción meditada, sino un resorte. Había un tipo de violencia explícita que no quería que formara parte de mi vida.

Así que cuando a la ORT se le ocurrió la idea de meterse en los nuevos movimientos sociales, yo me impliqué directamente en paz y ecología, ya en España. Y ese fue el origen de mi relación con el tema de la paz.

\section{Amador Fernández Savater (AFS): ¿Y cómo llegaste a fundar el centro de paz} Gernika Gogoratuz?

JG: Viviendo ya entonces en Euskadi, a mí me atraía mucho Gernika como símbolo. Me parecía que allí había un símbolo de paz con una potencia enorme y donde podía entrar todo el mundo. En el interior de los símbolos se alberga mucha fuerza: no son cosas que estén en el cielo de las ideas, sino que forman parte de la tierra.

A mediados de los 80, yo andaba ya muy cansado de estar siempre en la acera de enfrente, siempre en un movimiento "contra" algo, opuesto a todas las instituciones. Así que presenté una propuesta de proyecto para un centro que se iba a abrir en Gernika con el objetivo de recordar el bombardeo. Me ofreció la posibilidad Joseba Arregui, por entonces portavoz del Gobierno Vasco y Consejero de Cultura, a quien conocí a través de mi mujer, Frauke, que era muy amiga de la suya.

Yo le dije a Arregui dos cosas. Por un lado, que íbamos a ser dependientes de las instituciones vascas, pero queríamos ser independientes en la toma de decisiones. 
Y él me respondió: "si es un centro con vinculación política a un partido no se lo cree nadie, tiene que ser un centro de la sociedad civil". Así que mientras estuvo amparado por Joseba Arregui, pudimos experimentar tranquilamente, sin tutela.

Lo otro que le dije fue: "mira, yo estoy dispuesto a trabajar el recuerdo, pero no para meterlo en el cajón del pasado, sino para abrirlo al futuro y a un horizonte de paz en convivencia”. Creo que sólo así el recuerdo puede tener fuerza en el presente. De ese modo puede interpretarse el nombre de Gernika Gogoratuz que significa recordando Gernika. "Gogoratuz" en euskera significa recordar, pero también comprometerse a algo y reflexionar. Un poco lo que Hegel designaba con la palabra “aufheben” (superación). Yo siempre decía: "es como Hegel, pero más vital". ${ }^{1}$

Pronto nos dimos cuenta de que Gernika era un símbolo con mucha fuerza, bien apoyado por su gente y su ayuntamiento, pero sin base histórica. Porque la historia del bombardeo era la historia sacada de las declaraciones de los pilotos alemanes y del diario que escribió su comandante Wolfram Von Richthofen. Entonces lanzamos el proyecto de recoger los testimonios orales de los supervivientes para contar la historia de otro modo, desde abajo. Fue una iniciativa bien bonita, donde aprendí mucho sobre la fuerza del recuerdo.

\section{Paz positiva y paz negativa}

\section{AVH: Dices que la paz está mal definida, ¿a qué te refieres?}

JG: Bueno, creo que no importa tanto si la paz está bien o mal definida, sino por qué la paz es tan débil y yo respondo que es tan débil porque está mal definida. La definición dominante dice que la paz es ausencia de guerra y violencia. La paz, definida así, negativamente, sería algo de muy baja saliencia. Es decir, se quiere la paz, pero se quieren otras cosas más que la paz y para conseguirlas, en el choque con los que quieren distinto, se usa la violencia que es el medio más directo. ¿Por qué esa mala definición hace que la paz sea de baja saliencia? Porque así definida sólo se ve el esqueleto de la paz, la dimensión negativa.

\footnotetext{
1. Die objektive Logik (1812/13; 1. A. 1831), in: Walter Jaeschke (Hg.): Georg Wilhelm Friedrich Hegel. Gesammelte Werke Band 11, Hamburg 1978, 57f. | Comentario en castellano: Jacinto Rivera de Rosales/UNED/"La Aufhebung hegeliana" en: http://www.filosofiayliteratura.org/critica/aufhebung.htm | Comentario en inglés: Kai Froeb "Sublation" en: http://www.hegel.net/en/sublation.htm
} 
Los teóricos de la paz, como Johan Galtung², John Paul Lederach³ o Adam Curle4, dicen que la paz tiene dos caras: la paz positiva y la paz negativa. La paz negativa es el no a la violencia y ese "no" se entiende muchas veces desde unos enfoques dialécticos, partiendo de que la violencia es la negación de la vida. Es algo que encontramos ya en Marx, ${ }^{5}$ por ejemplo, cuando afirma que el proletario encarna al género humano porque es la negación del privilegio y el privilegio es la negación del ser humano. Por el "pasodoble del no", la negación de la negación, el proletario encarna el género humano. Y eso condujo a Marx a decir que los proletarios, cuando se rebelan, no tienen nada que perder salvo sus cadenas. Pero el proletario, por muy miserable que sea, incluso partiendo de la definición latina del proletario como quien no tiene más que su prole, no es verdad que no tenga nada que perder, porque todos sabemos que perder un hijo es una de las pérdidas más terribles que pueda haber.

En esta definición de la paz como un Jano bifronte, además de la paz negativa está la otra cara de la paz, la paz positiva. Pero no encuentro una definición sostenible de lo que es. Parecería que es una distinción entre violencia de alta y de baja intensidad, pero el dolor y la destrucción humana que causa la violencia de baja intensidad son muchas veces tan grandes como los que provoca la violencia de alta intensidad. No me parece que la diferencia interesante esté ahí.

Entonces, en Gernika Gogoratuz nosotros nos atrevimos hace ya mucho tiempo a dar una definición. No solo hay que atreverse a pensar, sino que muchas veces creo que también hay que atreverse a redefinir las cosas. Entonces, redefinimos la paz positiva como el engarce de vidas. Algo muy amplio, porque se trata de una inmensa malla. $\mathrm{Y}$ para concretar esta imagen partimos de algo muy concreto: nos han dado la vida seres emparejados, nuestra vida ha nacido cobijada en el vientre de una mujer, eso lo debemos. Y cuando hemos salido de ese vientre hemos seguido unidos a esa mujer. La paz positiva no tiene por tanto que pasar por dos no. Es directamente un sí a la vida. A una vida ancha, que quiere vivir y vive compartiendo con otros. Hay paz positiva en una sociedad allí donde cada vida da y recibe vida más allá de balances contables, donde hay estructuras que sostienen ese tejido cálido y una cultura que alienta compartir afectos y actos.

2. Consultar Johan Galtung (2003). Paz por Medios Pacíficos, Bilbao, Bakeaz/Gernika Gogoratuz.

3. Consultar John Paul Lederach (1998). Construyendo la Paz: Reconciliación sostenible en sociedades divididas, Bilbao, Bakeaz/Gernika Gogoratuz.

4. Adam Curle (1958). Peace With Work to Do: The Academic Study of Peace. Berg Publishers.

5. Consultar K. Marx y F. Engels (1998). Manifiesto comunista, introducción de Eric J. Hobsbawm, traducción de Elena Grau Biosca y León Mames, edición bilingüe, Barcelona, Crítica. También se sugiere consultar K. Marx (1976). Elementos para una crítica de la economía política (Grundrisse), Siglo XXI, Buenos Aires. 
Entonces, para resumir, diría que normalmente la paz positiva no se tiene en cuenta y resuena mucho más la dimensión de la paz negativa. Creo que incorporar la definición de paz positiva como engarce de vidas ayuda a darle más saliencia a la paz. Pero también hay que añadir: la paz positiva, que nosotros hemos renombrado como "paz de vida" o "paz viva", sólo tiene fuerza engarzada con la noción de paz negativa. Aislada, es puro "buenismo". Niega que esas vidas se engarcen en una realidad que también está llena de violencia. Nuestras vidas se sostienen y tienen sentido gracias a que vivimos inmersos en la paz positiva, en la vida compartida, en la malla de engarces. Pero ese tejido se enfrenta constantemente a los tremendos desgarrones de la violencia. Y es en atención a los dos lados de la paz cómo creo yo que puede surgir algo. Esa tensión hay que revelarla en los mismos relatos.

\section{AFS: Los vínculos que se tejen en esa malla, esos engarces, ¿de qué tipo son?}

JG: En el tejido de paz positiva, definiéndola por un momento en abstracto como algo separado de la violencia aunque ambas están mezcladas en la realidad, podemos encontrar muchos engarces distintos. Voy a contar una historia dentro la cual podemos encontrar y distinguir algunos de esos engarces.

Es una historia que me contó hace unos 15 años en Alberta, Canadá, un judío muy conocido en Israel. Me contó que de niño él vivía en Austria durante la ocupación nazi y que su padre tenía una tienda. Un día agarran al padre y le meten preso. Entonces, su familia contacta a los guardianes para sobornarles y que liberen al padre. Y lo consiguen: el padre se fuga disfrazado de mujer. En la tienda vigilada por las SS, al crío de 4 años, ya enterado de la huida de su padre, se le escapa inocentemente: "mi padre va a venir mañana”. Pero los SS allí presentes se echan a reír y no hacen ni dicen nada.

En esta sencilla historia, hay engarces de todo tipo. Por un lado, el vínculo de la familia que es un vínculo de ayuda con alguien del propio grupo. Es el vínculo más evidente. Incluso el enemigo acepta a veces estos vínculos: por ejemplo cuando se acusa a alguien de un delito, su pareja no está obligada a dar testimonio en su contra ante la ley, se puede negar. Otro de los engarces que encontramos en la historia es el soborno de la familia a los guardianes para ayudar a liberar al padre. Es un engarce negro de la familia que se salta morales convencionales y funciona. Por último, el gesto de los SS que hacen como si no hubiesen escuchado nada y desobedecen su deber que era denunciar. Este es el engarce que a mí me gusta llamar "hebras de paz de vida": las acciones de la persona de un bando que, rompiendo la disciplina que ese bando impone, echa una mano de ayuda, muchas veces salvadora, a una persona del bando enemigo en gran necesidad o peligro.

No siempre es fácil distinguir las hebras de paz de vida en la malla de la paz positiva. Los engarces que te unen a alguien del propio grupo pueden tener un borde duro con 
el afuera, ser excluyentes, como la camaradería entre los nazis o el terrible grito de "ia mí la legión!". Las "hebras de paz de vida" no se sabe siempre a ciencia cierta si lo son o no. Hay casos en que es clarísimo, pero no siempre. Hay toda una complejidad de la malla. Pero lo más importante es acercarse ahí, no reducir la paz a paz negativa. No ver la violencia como total. La realidad no es una mera sopa de violencias, sin ningún otro condimento. Quien te dice: “Desengáñate, sé realista: aquí lo único que cuenta es la violencia, se está engañando a sí mismo y en vez de ser realista es idealista negro.

\section{Hebras de paz de vida}

AVH: ¿Qué efectos positivos crees que tiene ese rechazo a ver la violencia como total, ese rescate en el que te empeñas de las hebras de paz positiva?, ¿Por qué es tan importante?

JG: La paz de vida desplaza la mirada, cambia todo el paisaje. Por ejemplo, durante una de las conferencias en las que participé en esta visita a México, en Puebla, un profesor desarrolló una ponencia muy interesante. Decía que el miedo es el principal arquitecto de la ciudad. Eso se ve muy claro aquí en México DF o en Colombia: hay vallas, verjas, controles por todos lados. Pero yo le pregunté si la necesidad y el afecto no son también arquitectos de la ciudad y él me respondió que sí. Se suele presentar la violencia como arquitecta de todo, esa es la mirada dominante, pero en cuanto se señala la realidad de la paz positiva hay un vuelco en la percepción, la gente se abre. Quiero decir que es preciso y muy necesario descubrir los mil pliegues de la violencia, pero si tenemos a la violencia como total, entonces percibimos una realidad que nos hace impotentes y adquirimos el síndrome de la indefensión aprendida.

\section{AVH: ¿Cómo sería ese síndrome de indefensión aprendida?}

JG: Está definido por psicólogos sociales, yo me enteré de su existencia hace ya más de treinta años. Hannah Arendt ${ }^{6}$ decía que el mal no es radical, puede ser extremo, pero si se presenta la violencia como total ya no es la violencia real que hay en el mundo, porque en el mundo real, y en el pasado que nos llega a través de la memoria, siempre hay una tecla más en el teclado del piano y es una tecla que cambia toda la melodía.

6. Consultar Hannah Arendt (1963). Eichmann in Jerusalem: A Report on the Banality of Evil, New York, The Viking Press. También se sugiere consultar Hannah Arendt (1958). The Human Condition, University of Chicago Press. 
¿Os acordáis de la historia del niño que grita “¡El rey está desnudo!” cuando todos los súbditos adulan sus vestidos, en El Conde Lucanor del Infante Don Juan Manuel? Las hebras de paz de vida hacen un poco el mismo efecto. Si se mete una hebra de paz de vida, que es como un embajador de toda la malla de paz viva, cambia toda la perspectiva. El tejido de los engarces de apoyo siempre parece encogido y rasgado, pero nunca lo está del todo. Lo que pasa es que en pasados marcados por la violencia y el trauma, los engarces de paz de vida desaparecen de la superficie. Pero siempre quedan un par de hebras en el tejido que parece roto. Señalar esas hebras no es un acto heroico, como no lo es el del niño del cuento, pero hace que de pronto miles de ojos pueden ver algo que no se ve y que no se quiere ver. El niño, aún pequeño como es, transforma toda una relación de poder y las hebras, también frágiles como son, pueden transformar también todo el paisaje.

\section{AFS: ¿Nos puedes poner algún ejemplo de ese desplazamiento de la mirada?}

JG: En el marco del proyecto "Hebras de paz de vida", conocí a Svetlana Broz. Svetlana es cardióloga y periodista serbo/croata, también la nieta del mariscal Josip Broz Tito. Cuenta que, tratando como médico a heridos de la guerra de Yugoslavia, una y otra vez se encontraba con pacientes que querían y necesitaban contar historias. Y para su sorpresa en muchos casos eran historias que hablaban bien de alguien que se encontraba en el bando enemigo. Un croata que narra cómo un serbio le salva la vida, un musulmán que cuenta cómo un croata le ayudó a escapar, muchísimas historias así.

Svetlana se puso a recoger este tipo de historias y pronto tuvo un montón de relatos de hebras de paz de vida. En 2006 los publicó en un libro con el título Gente de bien en tiempos de mal7. Svetlana cuenta que el libro se ha difundido mucho en Serbia, en Croacia, en Bosnia, y ha tenido efectos muy positivos. Por ejemplo, deconstruye la imagen de enemigo que tienen unos sobre otros, los serbios sobre los croatas, etc. Porque los testimonios hablan de tal serbio y tal croata que ayudó a una persona en apuros del bando contrario, a veces arriesgando la vida, a veces desplegando un ingenio maravilloso e increíble, disfrazando al otro y demás. Esa deconstrucción de la imagen de enemigo (la demonización completa del otro) ayuda a que sanen las relaciones entre los pueblos. Y favorece además la autoestima de cada cual, de cada grupo, porque esos testimonios te hacen ver a tu grupo o a otros grupos como algo muy diferente de una simple banda de asesinos o criminales. Es en ese sentido que digo que las hebras de paz de vida desplazan la mirada y cambian la perspectiva.

7. Hart, L. K. (2004). Good People in an Evil Time: portraits of complicity and resistance in the Bosnian War. New York: Other Press. 
AVH: ¿Y qué pasa cuando no hay bandos definidos? Por ejemplo, pienso en México, donde no hay abiertamente una guerra declarada, aunque se llame así periodísticamente. Pero el EZLN8 por ejemplo, no podemos decir que sea un "bando". Rechaza la guerra como tal, rechaza constituirse en bando, ajustar cuentas, etc. Abundan en el mundo guerras con bandos definidos, pero también estas otras situaciones asimétricas de conflicto como México. Me pregunto, por ejemplo, qué hace que un niño sea sicario y pierda su humanidad. Creo que tiene más que ver con condiciones sociales, estructurales, de pobreza y violencia que llevan al niño a decir al final: "mejor vivir un ratito como rey que una vida entera como mendigo".

JG: Me parece un poco esquemático definir los bandos en general y luego ubicarnos por bandos. A veces es la propia experiencia la que marca en qué bando estás y cuál es el bando distinto o el enemigo. Cuento una historia mexicana: es un abogado que trabaja en una empresa de seguros y viene una mujer a reclamar el seguro de vida de su marido muerto. La empresa analiza y dictamina que el marido se quitó la vida y la mujer no tiene por tanto el derecho a la cantidad asegurada. El abogado se encuentra con la mujer y ella le dice: "mire, entérese de lo que ha pasado: mi marido se ha quitado la vida porque estaba con un cáncer terminal y sus últimos meses iban a ser un infierno de dolor. Entonces, de acuerdo conmigo, se quitó la vida". Y el abogado responde: "vamos a hacer una cosa, yo voy a rechazar su solicitud, pero la voy rechazar con un argumento jurídicamente falso y entonces usted va a poder reclamar y ganar". Fíjate la astucia que desplegó el abogado para poder romper la fidelidad a su "bando" y echar una mano salvadora al lado contrario, arriesgando su misma profesión. Ahí hay una hebra de paz de vida clarísima. ¿Qué quiero decir? Pues que los bandos no son algo homogéneo. Son heterogéneos, tienen mucha vida y cambio interno. Y muchas veces, como en este caso, los define la propia situación.

También quería decir algo sobre los niños sicarios. John Paul Lederach, que es una de las estrellas de la investigación sobre la paz, ha escrito un libro precioso que se llama La imaginación moral 9 . Lo que hace es pensar la moral por fuera del cumplimiento del deber. La imaginación moral es por ejemplo la de alguien enamorado que ejercita su creatividad pero no para cumplir un deber, sino para alegrar a la persona que quiere. ¿Por qué digo esto? Porque la hija de Lederach ha estudiado antropología y también

8. El Ejército Zapatista de Liberación Nacional es una organización política militar formada durante la década de los 1980 en el sureste mexicano. El 1 de enero de 1994, con un levantamiento armado que les dio visibilidad internacional, comenzaron la rebelión indígena más importante en la historia de México, combinando estrategias militares con innovadores ejercicios de organización política a lo largo de las dos décadas posteriores. Actualmente, si bien los zapatistas mantienen milicianos armados, la apuesta de las comunidades indias chiapanecas que lo conforman han apostado por la consolidación de las zonas autónomas zapatistas, donde las comunidades se autogobiernan con base en los sistemas normativos de los pueblos originarios a través de las llamadas "Juntas de buen gobierno". Para más información sobre este movimiento puede verse: http://enlacezapatista.ezln.org.mx/

9. Lederach, J. P. (2008). La imaginación moral. Bogotá D.C.: Editorial Norma. 
está muy metida en asuntos de mediación. Tiene como 25 años y ha estudiado el tema de cómo los niños soldados se reincorporan a la sociedad en África del oeste.

Ella nos ha relatado que cuando acaban las hostilidades, los niños ya no pueden volver a su pueblo. Han asesinado y torturado a gente del propio pueblo. Entonces se quedan fuera del pueblo, viviendo alrededor de un árbol al que llaman el "árbol de la vergüenza”. Son zonas que permiten por el clima vivir al aire libre. Se quedan ahí en el monte, mirando al pueblo, con toda la pinta de niños soldados: con greñas, sucios, etc. Entonces las madres, las madres en general, no las suyas, van al árbol de la vergüenza y lo primero que hacen es lavarles y cortarles el pelo. O sea, reproducen la situación de cuando eran niños pequeños y les lavaban y peinaban. Luego se ponen a hablar con ellos y a cantar juntos las canciones de cuna de cuando niños. Y finalmente van juntos al pueblo, primero cantando canciones muy tristes y según van llegando al poblado, canciones muy alegres.

¿Cómo se puede interpretar este proceso? Es verdad que los niños soldados han perdido la humanidad, pero recuerdan los actos de paz y cariño que han vivido como niños y el contacto con las madres aviva el recuerdo. Por tanto, de nuevo, la violencia no es total. Para reinsertarse como parte de la comunidad resuelven un pasado en el que han sido ejecutores de violencia evocando un pasado anterior, en el que eran niñitos queridos por sus madres. Van a otro pasado más lejano. Siempre se tiende a decir que todo es violencia. Es de lo que estamos hablando a lo largo de toda la entrevista. Pero la vida de estos niños soldados no ha sido solo violencia. Han vivido experiencias que no eran de violencia pero que la violencia ha enterrado. Y en cuanto las descubres entiendes todo distinto. Lo que pasa con el niño del cuento que gritó "El rey está desnudo". Muestra una verdad que estaba tapada por otra.

Otra vez, en esta visita a México, en otra de las charlas, me preguntaron “¿cómo se alcanza la paz?" Y yo respondí: la paz ya la tenemos alcanzada, porque en nuestra vida estamos constantemente viviendo sostenidos por estos engarces de paz de vida, cuando nos saludamos, cuando compartimos, en toda la cortesía con la que nos tratamos, con todas las formas de darnos aliento unos a otros. Estamos ya viviendo en ella. La paz no es una cuestión de "suma cero": hay un kilo más de violencia y un kilo menos de paz. Eso solo pasa si cogemos únicamente la paz negativa. Pero si atendemos a la paz de vida, puede haber perfectamente mucha violencia y a la vez mucha paz de vida. 


\section{Acampada Sol: una pequeña ciudad hecha de paz viva}

AFS: Te queríamos preguntar también por el 15M o los "indignados" en el Estado Español. Ha sido un movimiento que ha tenido mucha importancia para ti. ¿En qué sentido se vincula un movimiento político contra la crisis con la cuestión de la paz, ¿tienen algo que ver?

JG: El 15M tiene un tremendo potencial que creo que hace falta entender mejor para que se desarrolle aún más. Y lo señaló muy bien Eduardo Galeano que estuvo por la acampada de Madrid y también en Barcelona y dijo: "ustedes ya han hecho todo". A diferencia de Podemos (el partido político) que promete todo, el 15M no prometía nada. Lo que hace el 15M es decir: la realidad que vivimos no es la realidad que nos cuentan que vivimos, "lo llaman democracia y no lo es". Con lo cual deslegitima al poder. Porque antes podía presentarse alguien, como el ex-presidente Felipe González hizo, diciendo algo como: "yo soy un cristo en la cruz, me he sacrificado por España”. Y ahora eso se acabó. El 15M redefine la realidad entendiendo que parte de esa realidad es la dignidad, por eso son los indignados. Y no se trata de la dignidad propia, sino del trato que recibe esa dignidad por la estructura de poderes que gobierna el mundo y la mutila y asfixia. No es una realidad entendida en sentido positivista, sino una realidad desde la cual se deslegitima al poder.

El 15M era abierto porque consideraba que cualquiera tiene razones para indignarse, cualquiera puede considerar que su dignidad ha sido tratada desde el poder establecido de una forma indignante. Entonces, como desde ahí se apela a todo ser humano, el que llegaba no lo hacía como segundón ni como un huésped bienvenido, sino como una persona que tiene una indignación propia y que a la vez es compartida, porque no tiene bordes y se estructura de forma que no hay que aceptar una cúspide o liderazgos para poder ser participante del movimiento.

En Puebla conocí a este profesor que os contaba que decía que el miedo era el arquitecto de la ciudad en América Latina. Y yo en respuesta hablé de la acampada de Sol (plaza pública madrileña). Y conté cómo aquello era una pequeña ciudad en la que el arquitecto no era el miedo, sino los engarces de paz viva. La malla de paz viva era el arquitecto. Una ciudad abierta, acogedora a todo el mundo, una ciudad de cuidado por todos los poros, en la que cada cual encontraba su lugar, tanto la abuela que ayudaba con unas croquetas que había cocinado hasta el niño que pasaba allí las primeras vacaciones de su vida acogido por todos y no inseguro, sino acariciado de forma no agobiante por la gente que estaba allí. Era una materialización de la paz viva real, mágica... e inestable. Al cabo de un mes de acampada, fue la gente que estaba durmiendo y sosteniendo esa ciudad como ciudad de paz viva los que comenzaron a decir: "tenemos que irnos a otro lado". Mientras que había grandes oradores diciendo: "no podemos dejar la plaza 
porque para Grecia es un ejemplo", tal y cual, esos otros decían que los problemas de convivencia (machismo, agresiones) se estaban haciendo ya insuperables y no se podían impedir. Lo cual también muestra que la paz de vida sola, no es sostenible, necesita entrar en este juego con la paz negativa y con la respuesta a la violencia. Los oradores hablaban desde fuera y los otros desde dentro, en contacto con la paz viva.

La membrana protectora de la pequeña ciudad de Sol era la no violencia. El 15M no hacía a nadie enemigo, ni siquiera a la policía. Eso era una constante. Y funcionó bien durante esas cinco semanas, aunque siempre se diga que la paz no sirve para nada y que la violencia es lo más práctico al final.

\section{Librar a la memoria de la violencia del vencedor}

AVH: Sobre la vida diaria y la violencia en México, te preguntaría ¿cómo desplazarnos de ese síndrome de indefensión/impotencia aprendida? ¿Cuál es ahí el trabajo de la memoria? ¿Sirve la memoria en pleno enfrentamiento o solo cuando el conflicto ha acabado? ¿Sirve la memoria como una llave?

JG: La potencia de la violencia es un mito. La violencia se ve potente por su capacidad destructora, pero nunca sirve para alcanzar los objetivos por la que se ostenta. Me explico: las armas nucleares pueden destruir mil veces a la humanidad, pero lo que pasa es que solo hay una humanidad que sigue existiendo y con futuro, por lo que entonces son 999 veces impotentes.

Hay un gesto muy macho que es hacer ostentaciones de potencia que en realidad esconden la impotencia en la que se vive: "te parto la cara", cuando en realidad nunca se le ha partido la cara a nadie. Y desde ahí se presenta a la paz como impotente. Porque los caminos de la paz no son tan directos y rectos como los caminos de la violencia. Lo que pasa es que los caminos de la violencia no conducen a realizar el objetivo que la activa.

Realmente hay que analizar siempre qué relación de fuerzas hay de un lado a otro. $Y$ es un fetiche entender que la superpotencia puede controlar todo. La pérdida de poder de Estados Unidos (EEUU) - después de las dos guerras de Irak- es una gran crisis que lleva según todos los investigadores políticos a sustituir a Bush por Obama, aunque sea para que haga lo mismo pero de otra manera. La pérdida de poder de EEUU es notoria. Hoy mismo, China va adquiriendo más poder que EEUU, porque el poder de EEUU es poder militar de ejercer violencia y China tiene en su inmensa producción de mercancías. Hay que buscar otras dinámicas de poder para explicar lo que sucede en el mundo y no sólo la violencia.

Sobre la memoria. ¿Cuándo se ejercen las hebras de paz de vida? En el momento más duro del conflicto. Eso desde luego. ¿Cuándo se perciben? Ahí entra en juego la 
memoria. La hebra de paz rompe con la violencia que ejerce sobre todo el vencedor. $Y$ son los vencedores los que escriben la historia. Hay que librar a la memoria del dictado de la violencia del vencedor. Cuando los vencedores escriben la historia hay un lugar muy estrecho para sus víctimas. La víctima, históricamente, después de sufrir la violencia, ha tenido siempre que andar agachada. Y solo cuando un general la sube a su carro y le dice "ahora puedes hablar", entonces se convierte en persona pública. Solo cuando su discurso le conviene a la causa del vencedor.

Lo que ahí se promueve es la totalización del horror y el dolor. Porque de un lado hay víctimas y del otro lado no emana nada humano. Solo hay violencia en el otro lado, ninguna humanidad. Entonces la víctima es cautiva del vencedor que la sube al carro. Y de ahí que las víctimas tengan tendencia a ser víctimas vengadoras. Sin embargo, en ámbitos de mayor libertad, donde el vencedor no tiene una fuerza tan totalitaria, puede haber una maduración de la víctima que dice: "ahora voy a hablar yo con mis palabras, no a decir el discurso que me marca el vencedor que me ha subido al carro". Puede ser que ahí pase a ser una víctima muy secundaria, menos escénica, porque los escenarios están preparados por el vencedor.

En EEUU, hay un grupo maravilloso con el que yo he trabajado que se llama Peaceful Tomorrows (Mañana en Paz). ${ }^{10}$ Son 200 familiares de víctimas de los atentados del 11 de septiembre de 2001 que tienen una memoria absolutamente distinta a la que pretende el vencedor, no son víctimas vengadoras para nada. No tienen un líder que marque lo que tienen que hacer todas las víctimas. Tienen una mesa de dirección que cambia constantemente para que salgan personas y discursos distintos. Cuando en 2009 se dio esa gran discusión pública sobre si poner o no un centro islámico en la zona cero de Nueva York, la mayoría de víctimas expresaron un sentimiento anti-islámico, pero ellos recordaron que en el 11S habían muerto muchos musulmanes en las Torres Gemelas y varios de ellos tratando de salvar vidas, y que para ellos era un honor que se abriese ese centro. Están en contra de Guantánamo, han viajado a Irak y Afganistán a hermanarse con otras víctimas de la guerra global, hacen cosas increíbles. Prueban que las víctimas pueden cerrar el círculo de la violencia o acelerarlo. La víctima tiene esas dos opciones y está siempre invitada desde el poder a acelerar el círculo de la violencia, definiendo el bien como lo contrario del mal que estamos recibiendo desde el otro lado.

Hay que buscar la violencia, perseguirla en todos sus pliegues y recovecos, pero no totalizarla, no hacerla pasar por el todo. Apenas conozco México, pero creo que aquí hay una riqueza de paz viva increíble, en los gestos, en las miradas, en esa dulzura no servil que tiene la gente acá. Si se descarta todo eso, si la memoria no se nutre de ello, entonces la paz pasa a ser impotente. Cuando es todo lo contrario: la riqueza de paz de vida es lo más potente. 


\section{¿Qué son las hebras de paz?}

Son esos actos, las mayoría de las veces pequeños y casi imperceptibles pero otras veces desafiantes e incluso heroicos, que, en tiempos o situaciones marcados por el horror, terror, violencia letal o flagrantes injusticias, tienden una mano para ayudar o salvar a personas amenazadas o que sufren abusos y humillaciones por ser consideradas enemigas o ajenas. Estos actos se saltan las reglas y normas del grupo propio que exige obediencia y responden a motivos desinteresados. El proyecto "Hebras de Paz" se propone recoger estos relatos y reflexionar sobre su valor para una paz viva y positiva en convivencia. Desde hace varios años, varios profesores de secundaria de Madrid han llevado el proyecto "Hebras de Paz" a sus aulas encargando a sus alumnos que pregunten a sus mayores, familiares o personas allegadas si conocen o han vivido alguno de estos relatos. Después los presentan ante sus compañeros y buscan formas creativas de presentarlos. Hasta ahora se han recogido más de 300 relatos de cinco institutos. El 21 de noviembre de 2013 varios grupos de alumnos de Madrid viajaron hasta San Sebastián (País Vasco) al encuentro de "Ciudades destruidas" que se celebró en la ciudad. Allí se leyeron en público varios relatos de estas hebras de paz. ${ }^{11}$ 